\title{
Characteristics of patients with mental illness and persistent high-cost status: a population- based analysis
}

\author{
Claire de Oliveira PhD, Joyce Mason MSc, Paul Kurdyak MD PhD
}

Cite as: CMAJ 2020 December 14;192:E1793-1801. doi: 10.1503/cmaj.200274

\begin{abstract}
BACKGROUND: Most of the literature on high-cost users of health care has evaluated this population as a whole, but few studies have focused on high-cost patients with mental illness and whether they persist in the high-cost state. We sought to analyze this patient population in depth and determine predictors of persistency in the high-cost state.
\end{abstract}

METHODS: We used 8 years of longitudinal patient-level population data (20102017) from Ontario to follow high-cost patients (those in and above the 90th percentile of the cost distribution) with mental illness. We classified highcost status, based on the proportion of the study period that patients spent in the high-cost state, as persistent (6-8 yr), sporadic (1-2 yr) or moderate (3-5 yr).
We compared characteristics between groups and determined predictors of being a patient with mental illness and persistent high-cost status.

RESULTS: Among 52638 patients with mental illness and high-cost status, 18149 (34.5\%) were considered persistent high cost. These patients had higher mean annual costs of care (\$44714, 95\% confidence interval [Cl] $\$ 43724-\$ 45703)$ than patients with sporadic ( $\$ 23205,95 \% \mathrm{Cl} \$ 22741-$ $\$ 23668)$ and moderate $(\$ 31055,95 \% \mathrm{Cl}$ $\$ 30359-31751$ ) status, largely owing to psychiatric hospital admissions. Patients with mental illness and persistent high-cost status were more likely to be female, older, long-term residents of Ontario (information ascertained from the Immigrants, Refugees and Citizenship (anada Database), living in lowincome or urban areas, or to have comorbidities. The strongest predictors of persistent (v. sporadic) high-cost status were HIV (relative risk ratio [RRR] 4.32, 95\% Cl 3.08-6.06), psychosis (RRR $3.41,95 \% \mathrm{Cl} 3.25-3.58)$ and dementia (RRR 3.21, 95\% Cl 2.81-3.68).

INTERPRETATION: Among patients with mental illness and high-cost status, persistence in the high-cost state was determined mainly by psychosis and other comorbidities. Quality-of-care interventions directed at managing psychosis and multimorbidity, as well as preventive interventions to target patients with mental illness before they enter the persistent high-cost state, are needed.
$\mathrm{T}$ $o$ address rising health care costs, it is important to understand the composition of the population of patients with high-cost status. Most work on high-cost patients has considered this population as a whole. ${ }^{1-3}$ However, previous work has shown that policies and interventions designed to address quality of care and high health care spending in general will likely not apply to all subgroups of high-cost patients. ${ }^{4,5}$ Moreover, research has shown that high-cost patients are a heterogeneous population. ${ }^{6}$ For example, high-cost patients who use mainly mental health services are quite different from other high-cost patients - they are younger, live in poorer neighbourhoods and have different patterns of health care use., ${ }^{4,6}$ They also have high levels of comorbidity and incur over 30\% more costs than other high-cost patients, suggesting they may be a more complex population with higher needs. ${ }^{4,6}$
It is also important to understand whether high-cost patients remain in the high-cost state for long periods of time or whether this is a one-time occurrence. The few studies that have examined persistency in the high-cost state evaluated such patients as a whole and followed them for only 3 years. ${ }^{7,8}$ Although previous studies have found that individuals with mental illness are more likely to be patients with persistent high-cost status, ${ }^{9,10}$ no studies have specifically examined persistency in the high-cost state among patients with mental illness ${ }^{4}$ or followed these patients for long periods of time. ${ }^{11}$ The goal of this study was to provide an in-depth analysis of patients with mental illness and persistent high-cost status, using administrative health care data from Ontario, Canada's most populous province. 


\section{Methods}

\section{Study design and setting}

We undertook a retrospective, population-based, longitudinal cohort study of patients with mental illness and high-cost status to examine persistency in the high-cost state from 2010 to 2017 , using data from Ontario.

\section{Data}

We used administrative health care data available through ICES, in Toronto, to undertake our analysis. The ICES data repository contains individual-level linkable and longitudinal data on most publicly funded health care services for all legal residents of Ontario. It includes several health services databases, many of which have been validated and described in the literature, ${ }^{12}$ and used in costing analyses. ${ }^{4,6}$ We used the following databases: Discharge Abstract Database, Ontario Mental Health Reporting System, National Ambulatory Care Reporting System, Ontario Health Insurance Plan claims database, Ontario Drug Benefit claims database, National Rehabilitation Reporting System, Continuing Care Reporting System and Home Care Database. All databases were linked using unique encoded identifiers and analyzed at ICES, in compliance with Ontario privacy legislation. A full description of each database can be found in Appendix 1 (Table A1, available at www.cmaj.ca/ lookup/doi/10.1503/cmaj.200274/tab-related-content).

\section{Patient cohort}

We selected all adult patients (aged $18 \mathrm{yr}$ and older) who had at least 1 encounter with the Ontario health care system in 2010, the index year, and excluded those who did not have a valid health card number. Among these patients, we defined high-cost patients as all patients in and above the 90th percentile of the cost distribution, in line with previous work. ${ }^{4,6,8}$ This threshold enabled us to select a larger cohort of patients compared with other definitions (e.g., 95th percentile). Patients with mental illness and high-cost status were defined as those for whom costs related to mental health and addiction care accounted for $50 \%$ or more of their total costs. ${ }^{4}$ Previous research has shown that changing the threshold to $60 \%$ has little impact on the cohort definition, ${ }^{4}$ as mental health- and addiction-related costs account for most costs.

\section{Classification of high-cost status for patients with mental illness}

Costs related to mental health and addiction care were defined in line with previous work. ${ }^{4}$ We used a cost estimation algorithm, available at ICES, to estimate all direct health care costs incurred by patients and borne by the Ontario Ministry of Health. ${ }^{13}$ Details are provided in the appendix. We followed individuals from 2010 to 2017 (i.e., $8 \mathrm{yr}$ ) to examine whether they moved in and out of the high-cost state (i.e., above or below the 90th percentile of the cost distribution). Previous work has defined "patients in the persistent (or consistent) high-cost state" as those in the 80th percentile in all 4 half-year periods across 2 years, and "point high-cost patients" as the top users in the first year alone. ${ }^{11}$ Because this study indicated that patients with persistent high-cost status should incur high costs consistently and continuously over several periods, we defined these patients as those who remained in and above the 90th percentile of the cost distribution for 6 or more years (at any point) over the 8 -year study period (i.e., $75 \%$ of the analysis period). We defined patients with sporadic high-cost status as those in the high-cost category for 1 or 2 years, and patients with moderate high-cost status as those in the high-cost category for 3 , 4 or 5 years. Some patients (the attrition cohort) did not have data for all 8 years, owing to loss to follow-up (e.g., individuals who died, moved out of the province or were no longer eligible for public health care insurance in Ontario). We classified high-cost status similarly in the attrition and nonattrition cohorts and included both in the primary analysis.

\section{Analysis}

We compared the 3 patient groups in terms of sociodemographic characteristics - sex, age, migrant status, neighbourhood income quintile, rural residence and administrative health region - and presence of chronic conditions - rheumatoid arthritis, asthma, cancer, chronic obstructive pulmonary disease, diabetes, HIV, hypertension, congestive heart failure, Crohn disease or colitis, myocardial infarction, psychosis and dementia - which were determined through either disease registries (e.g., Ontario Cancer Registry) or validated algorithms. ${ }^{14-25}$ Given the lack of a validated algorithm to identify other relevant psychiatric chronic conditions, we attempted to determine the presence of mood disorders using at least 1 hospital admission record (with International Classification of Diseases, 10th Revision [ICD-10] codes F30, F31, F32, F33, F34, F38, F39, F53.0 and Diagnostic and Statistical Manual of Mental Disorders, 4th Edition [DSM-IV] codes 296.x, 300.4x, 301.13; all codes correspond to mood and affective disorders) or 2 physician billings (with diagnostic billing code 311 for

\begin{tabular}{llll}
$\begin{array}{l}\text { Table 1: Years in the high-cost state among patients with } \\
\text { mental illness and high-cost status in Ontario, by } \\
\text { nonattrition and attrition cohorts (2010-2017) }\end{array}$ \\
$\begin{array}{l}\text { No. of } \\
\text { years in } \\
\text { high-cost } \\
\text { state }\end{array}$ & $\begin{array}{c}\text { No. (\%) of all } \\
\text { patients in } \\
\text { high-cost state } \\
\boldsymbol{n}=\mathbf{5 2} 638\end{array}$ & $\begin{array}{c}\text { No. (\%) of } \\
\text { patients in } \\
\text { nonattrition } \\
\text { cohort* } \\
\boldsymbol{n}=\mathbf{4 5} 663\end{array}$ & $\begin{array}{c}\text { No. (\%) of } \\
\text { patients in } \\
\text { attrition } \\
\text { cohortt } \\
\mathbf{n}=\mathbf{6 9 7 5}\end{array}$ \\
\hline 1 & $9510(18.1)$ & $8491(18.6)$ & $1019(14.6)$ \\
\hline 2 & $8236(15.7)$ & $6858(15.0)$ & $1378(19.8)$ \\
\hline 3 & $6757(12.8)$ & $5540(12.1)$ & $1217(17.5)$ \\
\hline 4 & $5408(10.3)$ & $4403(9.6)$ & $1005(14.4)$ \\
\hline 5 & $4578(8.7)$ & $3747(8.2)$ & $831(11.9)$ \\
\hline 6 & $4337(8.2)$ & $3673(8.0)$ & $664(9.5)$ \\
\hline 7 & $4158(7.9)$ & $3641(8.0)$ & $517(7.4)$ \\
\hline 8 & $9654(18.3)$ & $9310(20.4)$ & $344(4.9)$
\end{tabular}

${ }^{*}$ Refers to the cohort of patients who had data for every year of the analysis (i.e., for all 8 years).

tRefers to the cohort of patients who did not have data for the entire analysis period (i.e., for all 8 years), owing to loss to follow-up (individuals who died, moved out of the province or were no longer eligible for public health care insurance in Ontario). Source: Administrative health care data housed at ICES, Toronto. 
Table 2 (part 1 of 2): Characteristics of high-cost patients with mental illness in Ontario by high-cost patient group, 2010

\begin{tabular}{|c|c|c|c|c|c|c|c|}
\hline Characteristic & $\begin{array}{c}\begin{array}{c}\text { No. }(\%)^{\star} \\
\text { of all } \\
\text { patients } \\
n=52638\end{array}\end{array}$ & $\begin{array}{l}\text { No. }(\%)^{\star} \\
\text { of } \\
\text { patients } \\
\text { with } \\
\text { persistent } \\
\text { high-cost } \\
\text { status } \\
n=18149\end{array}$ & $\begin{array}{l}\text { Standardized } \\
\text { differences } \\
\text { between } \\
\text { patients with } \\
\text { persistent } \\
\text { and sporadic } \\
\text { high-cost } \\
\text { status } \dagger\end{array}$ & $\begin{array}{l}\text { No. }(\%)^{\star} \\
\text { of } \\
\text { patients } \\
\text { with } \\
\text { sporadic } \\
\text { high-cost } \\
\text { status } \\
n=17746\end{array}$ & $\begin{array}{l}\text { Standardized } \\
\text { differences } \\
\text { between } \\
\text { patients with } \\
\text { sporadic and } \\
\text { moderate } \\
\text { high-cost } \\
\text { status } \dagger\end{array}$ & $\begin{array}{l}\text { No. }(\%)^{\star} \text { of } \\
\text { patients } \\
\text { with } \\
\text { moderate } \\
\text { high-cost } \\
\text { status } \\
n=16743\end{array}$ & $\begin{array}{l}\text { Standardized } \\
\text { differences } \\
\text { between } \\
\text { patients with } \\
\text { moderate and } \\
\text { persistent } \\
\text { high-cost } \\
\text { status } \dagger\end{array}$ \\
\hline Female & $\begin{array}{r}26929 \\
(51.2)\end{array}$ & $\begin{array}{l}9567 \\
(52.7)\end{array}$ & 0.08 & $\begin{array}{l}8646 \\
(48.7)\end{array}$ & 0.07 & $\begin{array}{l}8716 \\
(52.1)\end{array}$ & 0.01 \\
\hline Age, yr, mean \pm SD & $45.2 \pm 16.0$ & $47.1 \pm 15.6$ & 0.32 & $42.2 \pm 15.3$ & 0.25 & $46.3 \pm 16.6$ & 0.05 \\
\hline \multicolumn{8}{|l|}{ Migrant status $\ddagger$} \\
\hline Long-term resident & $\begin{array}{r}47925 \\
(91.1)\end{array}$ & $\begin{array}{l}16758 \\
(92.3)\end{array}$ & 0.10 & $\begin{array}{l}15882 \\
(89.5)\end{array}$ & 0.06 & $\begin{array}{l}15285 \\
(91.3)\end{array}$ & 0.04 \\
\hline Immigrant & $3442(6.5)$ & $976(5.4)$ & 0.10 & $1379(7.8)$ & 0.05 & $1087(6.5)$ & 0.05 \\
\hline Refugee & $1271(2.4)$ & $415(2.3)$ & 0.03 & $485(2.7)$ & 0.03 & $371(2.2)$ & 0.00 \\
\hline \multicolumn{8}{|c|}{ Neighbourhood income quintile } \\
\hline Missing & $500(1.0)$ & $235(1.3)$ & 0.07 & $116(0.7)$ & 0.03 & $\begin{array}{l}149 \\
(0.9)\end{array}$ & 0.04 \\
\hline $1-$ Low & $\begin{array}{l}14503 \\
(27.6)\end{array}$ & $\begin{array}{l}5609 \\
(30.9)\end{array}$ & 0.14 & $\begin{array}{l}4373 \\
(24.6)\end{array}$ & 0.05 & $\begin{array}{l}4521 \\
(27.0)\end{array}$ & 0.09 \\
\hline 2 - Medium low & $\begin{array}{l}10430 \\
(19.8)\end{array}$ & $\begin{array}{c}3572 \\
(19.7)\end{array}$ & 0.01 & $\begin{array}{c}3536 \\
(19.9)\end{array}$ & 0.00 & $\begin{array}{c}3322 \\
(19.8)\end{array}$ & 0.00 \\
\hline 3-Medium & $8807(16.7)$ & $2854(15.7)$ & 0.06 & $3172(17.9)$ & 0.03 & $2781(16.6)$ & 0.02 \\
\hline 4-Medium high & $8886(16.9)$ & $2800(15.4)$ & 0.07 & $3184(17.9)$ & 0.02 & $2902(17.3)$ & 0.05 \\
\hline 5-High & $9512(18.1)$ & $3079(17.0)$ & 0.05 & $3365(19.0)$ & 0.02 & $3068(18.3)$ & 0.04 \\
\hline \multicolumn{8}{|l|}{ Rural residence } \\
\hline Yes or missing§ & $4564(8.7)$ & $1239(6.8)$ & 0.13 & $1836(10.4)$ & 0.05 & $1489(8.9)$ & 0.08 \\
\hline No & $\begin{array}{l}48074 \\
(91.3)\end{array}$ & $\begin{array}{l}16910 \\
(93.2)\end{array}$ & 0.13 & $\begin{array}{l}15910 \\
(89.7)\end{array}$ & 0.05 & $\begin{array}{l}15254 \\
(91.1)\end{array}$ & 0.08 \\
\hline \multicolumn{8}{|l|}{ Administrative health region } \\
\hline 1 - Erie St. Clair & $1963(3.7)$ & $712(3.9)$ & 0.01 & $669(3.8)$ & 0.02 & $582(3.5)$ & 0.02 \\
\hline 2 - South West & $4071(7.7)$ & $1353(7.5)$ & 0.01 & $1387(7.8)$ & 0.00 & $1331(8.0)$ & 0.02 \\
\hline 3 -Waterloo Wellington & $2233(4.2)$ & $631(3.5)$ & 0.08 & $912(5.1)$ & 0.05 & $690(4.1)$ & 0.03 \\
\hline $\begin{array}{l}\text { 4- Hamilton Niagara } \\
\text { Haldimand Brant }\end{array}$ & $4866(9.2)$ & $1599(8.8)$ & 0.02 & $1685(9.5)$ & 0.00 & $1582(9.5)$ & 0.02 \\
\hline 5 - Central West & $1942(3.7)$ & $595(3.3)$ & 0.04 & $726(4.1)$ & 0.02 & $621(3.7)$ & 0.02 \\
\hline 6-Mississauga Halton & $2830(5.4)$ & $827(4.6)$ & 0.07 & $1084(6.1)$ & 0.03 & $919(5.5)$ & 0.04 \\
\hline 7 - Toronto Central & $\begin{array}{l}10652 \\
(20.2)\end{array}$ & $\begin{array}{l}4299 \\
(23.7)\end{array}$ & 0.17 & $\begin{array}{c}3004 \\
(16.9)\end{array}$ & 0.08 & $\begin{array}{l}3349 \\
(20.0)\end{array}$ & 0.09 \\
\hline 8 - Central & $\begin{array}{c}5502 \\
(10.5)\end{array}$ & $\begin{array}{c}1854 \\
(10.2)\end{array}$ & 0.02 & $\begin{array}{l}1941 \\
(10.9)\end{array}$ & 0.02 & $\begin{array}{c}1707 \\
(10.2)\end{array}$ & 0.00 \\
\hline $9-$ Central East & $4986(9.5)$ & $1694(9.3)$ & 0.01 & $1729(9.7)$ & 0.01 & $1563(9.3)$ & 0.00 \\
\hline 10 - South East & $2038(3.9)$ & $672(3.7)$ & 0.02 & $717(4.0)$ & 0.01 & 649 (3.9) & 0.01 \\
\hline 11 - Champlain & $6110(11.6)$ & 2205 (12.2) & 0.04 & 1927 (10.9) & 0.03 & $1978(11.8)$ & 0.01 \\
\hline $\begin{array}{c}12 \text { - North Simcoe } \\
\text { Muskoka }\end{array}$ & 1719 (3.3) & $525(2.9)$ & 0.04 & $642(3.6)$ & 0.02 & $552(3.3)$ & 0.02 \\
\hline 13 - North East & $2723(5.2)$ & $909(5.0)$ & 0.01 & $928(5.2)$ & 0.00 & $886(5.3)$ & 0.01 \\
\hline 14 - North West & $1003(1.9)$ & $274(1.5)$ & 0.05 & $395(2.2)$ & 0.02 & $334(2.0)$ & 0.04 \\
\hline
\end{tabular}


Table 2 (part 2 of 2): Characteristics of high-cost patients with mental illness in Ontario by high-cost patient group, 2010

\begin{tabular}{|c|c|c|c|c|c|c|c|}
\hline Characteristic & $\begin{array}{c}\text { No. }(\%)^{\star} \\
\text { of all } \\
\text { patients } \\
n=52638\end{array}$ & $\begin{array}{l}\text { No. }(\%)^{\star} \\
\text { of } \\
\text { patients } \\
\text { with } \\
\text { persistent } \\
\text { high-cost } \\
\text { status } \\
n=18149\end{array}$ & $\begin{array}{l}\text { Standardized } \\
\text { differences } \\
\text { between } \\
\text { patients with } \\
\text { persistent } \\
\text { and sporadic } \\
\text { high-cost } \\
\text { status } \dagger\end{array}$ & $\begin{array}{l}\text { No. }(\%)^{\star} \\
\text { of } \\
\text { patients } \\
\text { with } \\
\text { sporadic } \\
\text { high-cost } \\
\text { status } \\
n=17746\end{array}$ & $\begin{array}{l}\text { Standardized } \\
\text { differences } \\
\text { between } \\
\text { patients with } \\
\text { sporadic and } \\
\text { moderate } \\
\text { high-cost } \\
\text { status } †\end{array}$ & $\begin{array}{c}\text { No. }(\%)^{\star} \text { of } \\
\text { patients } \\
\text { with } \\
\text { moderate } \\
\text { high-cost } \\
\text { status } \\
n=16743\end{array}$ & $\begin{array}{c}\text { Standardized } \\
\text { differences } \\
\text { between } \\
\text { patients with } \\
\text { moderate and } \\
\text { persistent } \\
\text { high-cost } \\
\text { status } \dagger\end{array}$ \\
\hline \multicolumn{8}{|l|}{ Chronic conditions } \\
\hline Rheumatoid arthritis & $453(0.9)$ & $202(1.1)$ & 0.05 & $113(0.6)$ & 0.02 & $138(0.8)$ & 0.03 \\
\hline Asthma & $\begin{array}{c}10268 \\
(19.5)\end{array}$ & $\begin{array}{c}4040 \\
(22.3)\end{array}$ & 0.13 & $\begin{array}{c}3066 \\
(17.3)\end{array}$ & 0.04 & $\begin{array}{c}3162 \\
(18.9)\end{array}$ & 0.08 \\
\hline Cancer & $2188(4.2)$ & $837(4.6)$ & 0.08 & $537(3.0)$ & 0.09 & $814(4.9)$ & 0.01 \\
\hline COPD & $6456(12.3)$ & $2856(15.7)$ & 0.24 & $1434(8.1)$ & 0.16 & 2166 (12.9) & 0.08 \\
\hline Diabetes & 7659 (14.6) & $3790(20.9)$ & 0.34 & $1570(8.9)$ & 0.15 & $2299(13.7)$ & 0.19 \\
\hline HIV & $266(0.5)$ & $137(0.8)$ & 0.07 & $44(0.3)$ & 0.04 & $85(0.5)$ & 0.03 \\
\hline Hypertension & $\begin{array}{c}13700 \\
(26.0)\end{array}$ & $\begin{array}{l}5556 \\
(30.6)\end{array}$ & 0.25 & $\begin{array}{c}3508 \\
(19.8)\end{array}$ & 0.19 & $\begin{array}{l}4636 \\
(27.7)\end{array}$ & 0.06 \\
\hline Congestive heart failure & $1146(2.2)$ & 478 (2.6) & 0.10 & $221(1.3)$ & 0.10 & $447(2.7)$ & 0.00 \\
\hline Crohn disease or colitis & $555(1.1)$ & $234(1.3)$ & 0.05 & $133(0.8)$ & 0.04 & $188(1.1)$ & 0.02 \\
\hline Myocardial infarction & $615(1.2)$ & $234(1.3)$ & 0.05 & $140(0.8)$ & 0.06 & $241(1.4)$ & 0.01 \\
\hline Psychosis & $\begin{array}{c}22304 \\
(42.4)\end{array}$ & $\begin{array}{l}10010 \\
(55.2)\end{array}$ & 0.50 & $\begin{array}{l}5517 \\
(31.1)\end{array}$ & 0.20 & $\begin{array}{c}6777 \\
(40.5)\end{array}$ & 0.30 \\
\hline Dementia & $3143(6.0)$ & $1298(7.2)$ & 0.16 & 615 (3.5) & 0.17 & $1230(7.4)$ & 0.01 \\
\hline Mood disorders & $\begin{array}{r}29070 \\
(55.2)\end{array}$ & $\begin{array}{l}10493 \\
(57.8)\end{array}$ & 0.10 & $\begin{array}{l}9368 \\
(52.8)\end{array}$ & 0.04 & $\begin{array}{l}9209 \\
(55.0)\end{array}$ & 0.06 \\
\hline \multicolumn{8}{|c|}{$\begin{array}{l}\text { Note: } \mathrm{COPD}=\text { chronic obstructive pulmonary disease, } \mathrm{SD}=\text { standard deviation. } \\
\text { *Unless stated otherwise. } \\
\text { †Standardized differences }>0.1 \text { are considered clinically relevant. } \\
\text { †Migrant status was ascertained from the Immigrants, Refugees and Citizenship Canada database. } \\
\text { \$Given a very small proportion of patients with missing data on rurality, and to avoid issues regarding confidentiality, this category was combined with "yes." } \\
\text { IDefined as having } 1 \text { hospital admission for a mood disorder or } 2 \text { physician billing codes for a depressive or other nonpsychotic disorder within a 1-year period. } \\
\text { Source: Administrative health care data housed at ICES, Toronto. }\end{array}$} \\
\hline
\end{tabular}

depressive or other nonpsychotic disorders, not elsewhere classified) within a 1-year period. This algorithm has not been validated; therefore, it was considered only in a sensitivity analysis.

Cost analyses are described in Appendix 1. We undertook a trends analysis of costs over time using linear regression with a time trend for each patient group. We estimated a multinomial logistic regression mode ${ }^{26,27}$ on the pooled data (i.e., all $8 \mathrm{yr}$ of data combined) to determine the predictors of being a patient with mental illness and persistent or moderate high-cost status compared with having sporadic high-cost status, where the dependent variable for each patient was constructed using the previous definitions and its value repeated for each year that patients appeared in the data. This model controlled for the patient sociodemographic characteristics and chronic conditions described above, and calendar year indicators, all of which could vary over the 8 years. We exponentiated the model coefficients to obtain the relative risk ratio for a 1-unit change in the corresponding variable (where risk is measured as the risk of the outcome relative to the base outcome). ${ }^{26,27}$ We estimated clustered standard errors for all models to account for repeated observations on the same individual, where applicable.

\section{Sensitivity analysis}

We undertook sensitivity analyses, where an indicator of mood disorders was included in the model and where patients lost to attrition (i.e., all decedents and individuals ineligible for public health care insurance) were excluded from the analysis. Moreover, we estimated the odds of being a patient with mental illness and persistent high-cost status relative to having moderate and sporadic high-cost status, in line with previous work. ${ }^{8}$

\section{Ethics approval}

This study was approved by the Institutional Review Board at Sunnybrook Health Sciences Centre, Toronto. 


\section{Results}

Roughly $13 \%$ ( $n=6975)$ of individuals from the initial sample $(n=$ 52638 ) did not have data for all 8 years of the analysis, owing to loss to follow-up (Table 1). Based on our definitions, 34.5\% $(n=$ 18149 ) of patients were classified as having persistent high-cost status ( $18.3 \%$ patients were in the high-cost state for all $8 \mathrm{yr}$ ), $33.8 \%(n=17746)$ with sporadic high-cost status and $31.8 \%(n=$ 16743) with moderate.

The overall cohort had a mean age of 45 years and included roughly the same proportion of male (49\%) and female (51\%) patients (Table 2). Compared with patients with sporadic highcost status, those with persistent high-cost status were more likely to be older (mean age 47 v. $42 \mathrm{yr}$ ) or female $(52.7 \% \mathrm{v}$. $48.7 \%$ ); to live in low-income neighbourhoods (30.9\% v. $24.6 \%$ ) or urban areas (93.2\% v. $89.7 \%)$; and to have psychosis $(55.2 \%$ v. $31.1 \%)$, diabetes (20.9\% v. $8.9 \%)$, hypertension $(30.6 \%$ v. $19.8 \%)$, chronic obstructive pulmonary disease $(15.7 \% \mathrm{v}$. $8.1 \%)$, dementia (7.2\% v. $3.5 \%)$ or asthma (22.3\% v. $17.3 \%)$. Patients with moderate high-cost status were relatively similar to those with persistent high-cost status, except for a lower prevalence of psychosis $(40.5 \%$ v. $55.2 \%)$ and diabetes $(13.7 \%$ v. $20.9 \%)$.
Patients with persistent high-cost status had the highest mean costs in 2010 ( $\$ 44714,95 \%$ confidence interval $[\mathrm{Cl}]$ \$43724-\$45703), compared with patients with moderate (\$31 055, 95\% Cl \$30359-\$31 751) and sporadic high-cost status (\$23205, 95\% Cl \$22741-\$23668) (Table 3). In particular, 69\% of total costs for patients with persistent high-cost status were made up of costs of psychiatric hospital admissions alone (\$30 944, 95\% Cl \$29 956-\$31932), with other large costs incurred by physician services $(\$ 5818,95 \% \mathrm{Cl} \$ 5734-\$ 5902)$, outpatient prescription drugs ( $\$ 2947,95 \% \mathrm{Cl} \$ 2893-\$ 3000)$ and visits to hospital outpatient clinics (\$2666, 95\% Cl \$2608-\$2724). Combined, these costs made up $94.8 \%$ of total costs. The proportion of potentially preventable acute-care costs (defined through validated algorithms $)^{28,29,30}$ was small among all patients with mental illness and high-cost status (0.5\% of total costs). Between 2010 and 2017, costs decreased significantly in all 3 groups $(p<0.001)$ (Figure 1). The average annual decrease in costs was $\$ 2935$ for patients with moderate high-cost status, $\$ 2067$ for patients with sporadic high-cost status and $\$ 918$ for those with persistent high-cost status ( $p<0.001$ for all between-group comparisons). The appendix provides costs by health service for each year.

The risk of having persistent high-cost status, compared with sporadic high-cost status, was higher for older patients (v. ages

Table 3: Mean health care costs in 2010 for patients with mental illness and high-cost status in Ontario, by high-cost patient group and health service use*

\begin{tabular}{|c|c|c|c|c|}
\hline Health service & $\begin{array}{l}\text { All patients }(95 \% \mathrm{Cl}) \\
\qquad n=52638\end{array}$ & $\begin{array}{l}\text { No. of patients }(95 \% \mathrm{Cl}) \\
\text { with persistent } \\
\text { high-cost status } \\
n=18149\end{array}$ & $\begin{array}{l}\text { No. of patients }(95 \% \mathrm{Cl}) \\
\text { with sporadic } \\
\text { high-cost status } \\
n=17746\end{array}$ & $\begin{array}{l}\text { No. of patients }(95 \% \mathrm{Cl}) \\
\text { with moderate } \\
\text { high-cost status } \\
n=16743\end{array}$ \\
\hline Psychiatric hospital admissions & 21839 (21 407-22 270) & 30944 (29 956-31 932) & 14417 (13 983-14 852) & 19834 (19 166-20 503) \\
\hline Acute-care hospital admissions & $535(512-559)$ & $612(568-657)$ & $408(377-439)$ & $587(542-632)$ \\
\hline $\begin{array}{l}\text { Other hospital or institution-based } \\
\text { care }{ }^{-}\end{array}$ & $283(259-306)$ & $372(324-419)$ & $167(135-199)$ & $308(266-351)$ \\
\hline Hospital outpatient clinic visits & $2448(2418-2479)$ & $2666(2608-2724)$ & $2190(2145-2235)$ & $2487(2434-2540)$ \\
\hline Emergency department visits & $766(754-777)$ & $844(819-870)$ & $674(659-690)$ & $777(757-796)$ \\
\hline Other ambulatory care $\ddagger$ & $154(145-163)$ & $172(158-185)$ & $123(115-131)$ & $169(147-191)$ \\
\hline Physician services & $5146(5101-5190)$ & $5818(5734-5902)$ & $4380(4318-4442)$ & $5229(5148-5311)$ \\
\hline Outpatient prescription drugs§ & 1695 (1671-1720) & 2947 (2893-3000) & $702(679-725)$ & $1392(1357-1427)$ \\
\hline Home care & $252(242-262)$ & $339(318-360)$ & $144(133-155)$ & $272(254-290)$ \\
\hline Total costs & $33118(32676-33$ 560) & 44714 (43 724-45 703) & 23205 (22 741-23 668) & 31055 (30 359-31 751) \\
\hline $\begin{array}{l}\text { Potentially preventable acute-care } \\
\text { hospital admissions }\end{array}$ & $62(54-70)$ & $78(62-94)$ & $36(26-46)$ & $71(57-85)$ \\
\hline $\begin{array}{l}\text { Potentially preventable emergency } \\
\text { department visits }\end{array}$ & $117(114-120)$ & $139(134-145)$ & $93(89-97)$ & $118(114-123)$ \\
\hline Total potentially preventable costs & $179(170-187)$ & $217(200-235)$ & $129(118-140)$ & $189(173-205)$ \\
\hline \multicolumn{5}{|c|}{$\begin{array}{l}\text { *Costs are in } 2018 \text { Canadian dollars. } \\
\text { tIncludes inpatient rehabilitation, complex continuing care and long-term care. } \\
\text { †Includes same-day surgery, dialysis clinic visits and cancer clinic visits. } \\
\text { SIncludes outpatient prescription drugs for individuals covered under the public provincial drug plan (i.e., individuals aged } 65 \text { yr and older and those on social assistance). } \\
\text { ITotal potentially preventable costs are made up of costs of potentially preventable acute-care hospital admissions (determined through the Agency for Healthcare Research and Quality's } \\
\text { Prevention Quality Indicators) and potentially preventable emergency department visits (determined through the use of the Billings et al. algorithm, },^{28} \text { updated by Johnston et al. }\end{array}$} \\
\hline
\end{tabular}


18-44 yr, ages 45-64 yr, relative risk ratio [RRR] 1.19, 95\% Cl 1.131.25; ages 65-84 yr, RRR 1.70, 95\% Cl 1.52-1.89; ages 85-105 yr, RRR 1.23, 95\% Cl 0.93-1.62), but lower for men (RRR 0.79, 95\% Cl $0.75-0.82$ ), immigrants (RRR $0.59,95 \% \mathrm{Cl} 0.53-0.64$ ), refugees (RRR 0.64, 95\% Cl 0.55-0.74), rural dwellers (RRR 0.61, 95\% Cl 0.57-0.66) and those living in higher-income neighbourhoods (e.g., highest v. lowest neighbourhood income quintile, RRR 0.84, 95\% Cl 0.79-0.89) (Table 4). All chronic conditions were associated with increased risk of persistent high-cost status, with the highest relative risk ratios observed for HIV (RRR 4.32, 95\% CI 3.08-6.06), psychosis (RRR 3.41, 95\% Cl 3.25-3.58) and dementia (RRR 3.21, 95\% Cl 2.81-3.68). Associations of similar or slightly smaller magnitude were found for these variables with the risk of having moderate rather than sporadic high-cost status (Table 4). Appendix 1, Tables A3 and A4, provides the results of the multinomial logistic regressions including mood disorders and excluding patients lost to attrition, respectively; despite minor differences, the main findings were largely unchanged. Appendix 1 , Table A5, provides the odds ratios of being a patient with mental illness and persistent high-cost status versus being one with moderate and sporadic status; again, results were qualitatively the same.

\section{Interpretation}

Among our cohort of patients with mental illness and high-cost status, we found that more than 1 in 3 were patients with persistent high-cost status, while nearly 1 in 5 remained in the high-cost state for all 8 years of the analysis. Patients with mental illness and persistent high-cost status were slightly older, slightly more likely to be female, more likely to live in low-income or urban areas and to have psychosis, hypertension, asthma and diabetes, compared with patients with mental illness and with sporadic and moderate high-cost status. Their spending profile also differed - they had higher costs, and the proportion of costs due to psychiatric hospital admissions was larger than those of the other 2 groups. We found that the main predictors of being a patient with mental illness and persistent high-cost status were having HIV, psychosis or dementia. In a sensitivity analysis, we also found that having a mood disorder was predictive of being a patient with mental illness and persistent high-cost status. Results were largely unchanged when we dropped individuals who were lost to attrition over time. It is not surprising that having psychosis is predictive of being this kind of patient; previous research has found that patients with psychosis have high costs of care. ${ }^{31}$ Moreover, having

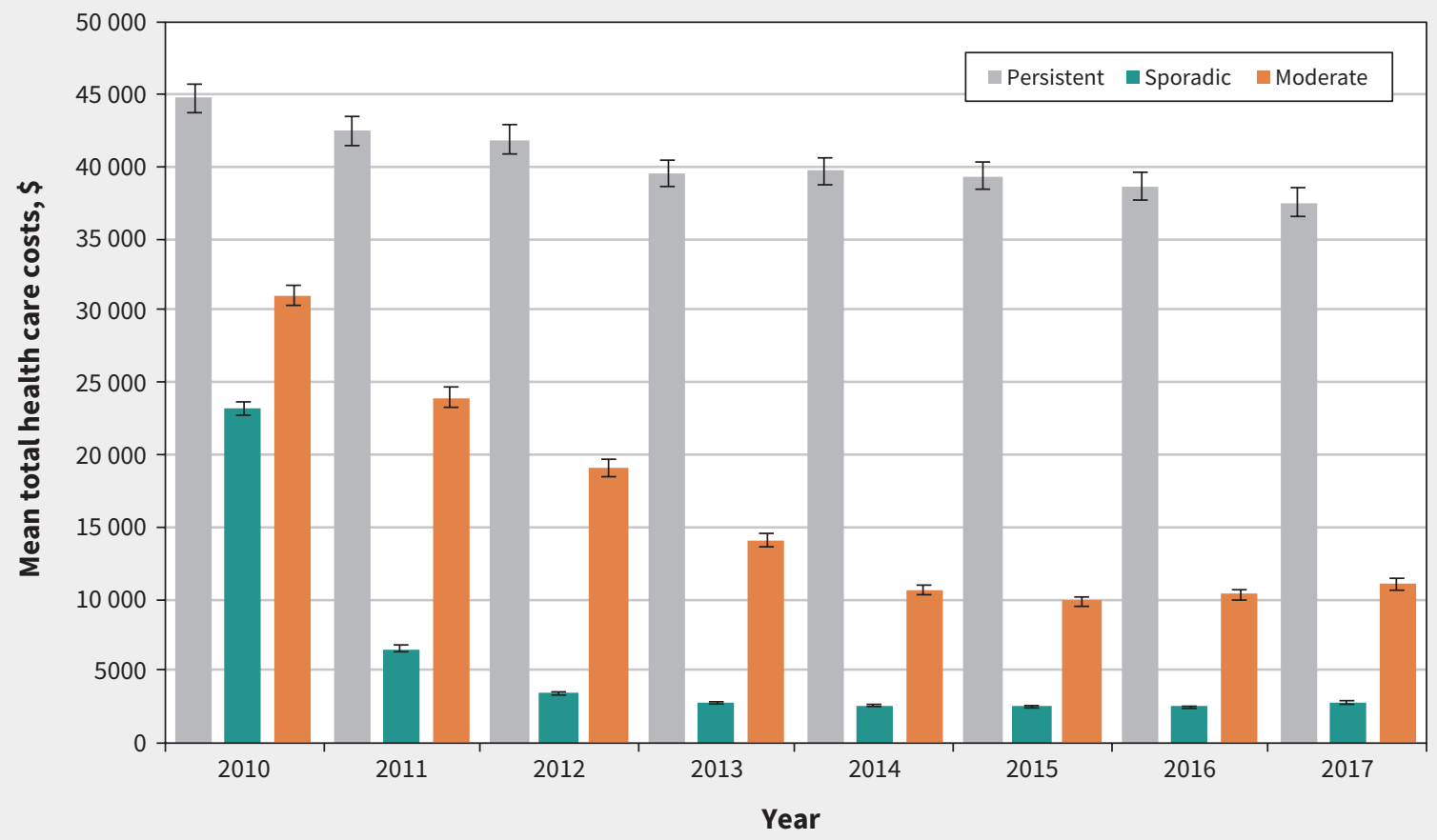

Figure 1: Mean total health care costs for patients with mental illness and high-cost status $(n=52638)$ in Ontario by high-cost patient group, $2010-$ 2017. Note: Costs are in 2018 Canadian dollars. Error bars represent $95 \%$ confidence intervals. Based on a trends analysis, we found that the average decreases in costs over time were greater for patients with moderate high-cost status ( $\$ 2935$ per year, $p<0.001)$, followed by sporadic status $(\$ 2067$ per year, $p<0.001)$ and persistent high-cost status ( $\$ 918$ per year, $p<0.001)$; all between-group differences were statistically significant $(p<0.001)$. Source: Administrative health care data housed at ICES, Toronto. 
Table 4: Pooled multinomial logistic regression: predictors of persistency in the high-cost state among patients with mental illness and high-cost status $(n=393511)^{\star}$ in Ontario, 2010-2017

\begin{tabular}{|c|c|c|c|c|}
\hline Variable & Predictor & Reference case & $\begin{array}{l}\text { Ratio of relative } \\
\text { risk of persistent } \mathrm{v} \text {. } \\
\text { sporadic high-cost } \\
\text { status }(95 \% \mathrm{Cl})\end{array}$ & $\begin{array}{l}\text { Ratio of relative } \\
\text { risk of moderate v. } \\
\text { sporadic high-cost } \\
\text { status }(95 \% \mathrm{CI})\end{array}$ \\
\hline Sex & Male & Female & $0.79(0.75-0.82)$ & $0.84(0.80-0.87)$ \\
\hline \multirow[t]{3}{*}{ Age group, yr } & $45-64$ & $18-44$ & $1.19(1.13-1.25)$ & $1.09(1.03-1.15)$ \\
\hline & $65-84$ & & $1.70(1.52-1.89)$ & $1.47(1.32-1.64)$ \\
\hline & $85-105$ & & $1.23(0.93-1.62)$ & $1.65(1.29-2.11)$ \\
\hline \multirow[t]{2}{*}{ Migrant statust } & Immigrant & Long-term resident & $0.59(0.53-0.64)$ & $0.80(0.73-0.87)$ \\
\hline & Refugee & & $0.64(0.55-0.74)$ & $0.74(0.64-0.85)$ \\
\hline \multirow[t]{5}{*}{ Neighbourhood income quintile } & 2-Medium low & $1-$ Low & $0.85(0.82-0.89)$ & $0.90(0.86-095)$ \\
\hline & 3-Medium & & $0.76(0.73-0.80)$ & $0.88(0.83-092)$ \\
\hline & 4-Medium high & & $0.77(0.73-0.81)$ & $0.87(0.83-0.92)$ \\
\hline & 5- High & & $0.84(0.79-0.89)$ & $0.92(0.87-0.97)$ \\
\hline & Missing & & $1.19(0.97-1.47)$ & $1.07(0.86-1.32)$ \\
\hline \multirow[t]{2}{*}{ Rural residence } & Yes & No & $0.61(0.57-0.66)$ & $0.82(0.76-0.88)$ \\
\hline & Missing & & $1.10(0.78-1.55)$ & $0.91(0.62-1.33)$ \\
\hline Rheumatoid arthritis & Yes & No & $2.04(1.62-2.59)$ & $1.36(1.06-1.73)$ \\
\hline Asthma & Yes & No & $1.35(1.27-1.42)$ & $1.11(1.05-1.18)$ \\
\hline Cancer & Yes & No & $1.82(1.62-2.04)$ & $1.76(1.58-1.97)$ \\
\hline COPD & Yes & No & $1.72(1.60-1.84)$ & $1.41(1.31-1.51)$ \\
\hline Diabetes & Yes & No & $2.09(1.97-2.22)$ & $1.35(1.27-1.44)$ \\
\hline HIV & Yes & No & $4.32(3.08-6.06)$ & $2.49(1.74-3.55)$ \\
\hline Hypertension & Yes & No & $1.50(1.42-1.58)$ & $1.33(1.26-1.40)$ \\
\hline Congestive heart failure & Yes & No & $2.26(1.89-2.69)$ & $1.86(1.56-2.21)$ \\
\hline Crohn disease or colitis & Yes & No & $2.16(1.74-2.68)$ & $1.62(1.29-2.02)$ \\
\hline Dementia & Yes & No & $3.21(2.81-3.68)$ & $2.01(1.75-2.29)$ \\
\hline Psychosis & Yes & No & $3.41(3.25-3.58)$ & $1.82(1.73-1.91)$ \\
\hline \multirow[t]{13}{*}{ Administrative health region } & 2 - South West & 1 - Erie St. Clair & $1.25(1.10-1.44)$ & $1.27(1.11-1.46)$ \\
\hline & 3-Waterloo Wellington & & $0.84(0.72-0.98)$ & $0.99(0.85-1.15)$ \\
\hline & 4-Hamilton Niagara Haldimand Brant & & $1.00(0.87-1.14)$ & $1.12(0.98-1.28)$ \\
\hline & 5 -Central West & & $0.92(0.79-1.08)$ & $1.10(0.94-1.29)$ \\
\hline & 6 - Mississauga Halton & & $0.96(0.83-1.11)$ & $1.12(0.97-1.29)$ \\
\hline & 7 - Toronto Central & & $2.06(1.82-2.33)$ & $1.55(1.37-1.76)$ \\
\hline & 8 -Central & & $1.22(1.07-1.39)$ & $1.20(1.05-1.37)$ \\
\hline & 9-Central East & & $1.13(1.00-1.29)$ & $1.14(1.00-1.31)$ \\
\hline & 10 - South East & & $1.24(1.06-1.45)$ & $1.18(1.01-1.38)$ \\
\hline & 11 - Champlain & & $1.47(1.29-1.67)$ & $1.38(1.21-1.58)$ \\
\hline & 12 - North Simcoe Muskoka & & $1.09(0.93-1.28)$ & $1.19(1.02-1.40)$ \\
\hline & 13 - North East & & $1.14(0.98-1.32)$ & $1.14(0.98-1.32)$ \\
\hline & $14-$ North West & & $0.97(0.79-1.18)$ & $1.20(0.99-1.45)$ \\
\hline \multirow[t]{7}{*}{ Year } & 2011 & 2010 & $1.03(1.03-1.04)$ & $1.05(1.04-1.05)$ \\
\hline & 2012 & & $1.04(1.03-1.05)$ & $1.03(1.03-1.04)$ \\
\hline & 2013 & & $1.03(1.02-1.04)$ & $0.99(0.98-1.00)$ \\
\hline & 2014 & & $1.01(1.00-1.02)$ & $0.94(0.93-0.95)$ \\
\hline & 2015 & & $0.98(0.97-0.99)$ & $0.92(0.91-0.92)$ \\
\hline & 2016 & & $0.94(0.93-0.95)$ & $0.90(0.89-0.91)$ \\
\hline & 2017 & & $0.90(0.89-0.91)$ & $0.88(0.87-0.89)$ \\
\hline
\end{tabular}


diabetes was also an important predictor of persistent high-cost status. Other work has found that individuals with psychosis are less likely to have optimal diabetes care than those without psychosis, resulting in higher rates of diabetes-related hospital admissions, ${ }^{32}$ which can lead to higher costs.

Few studies have examined persistency in the high-cost state, particularly among patients with mental illness. Using administrative data from Ontario, Wodchis and colleagues found that $30.7 \%$ of individuals in the top 5\% remained in the high-cost state from 2009 to $2011 .^{7}$ Figueroa and colleagues examined persistency in the high-cost state among a $20 \%$ sample of Medicare fee-for-service beneficiaries from 2012 to 2014 in the United States, using data on inpatient and outpatient care, physician services, tests and procedures, and drugs. ${ }^{8}$ They found that $28.1 \%$ of high-cost patients in the top $10 \%$ remained in the high-cost state for all 3 years. These patients were younger and more likely to be individuals of colour, live in lower-income areas, be Medicare eligible, and be dually eligible for Medicare and Medicaid compared with transient- and neverhigh-cost patients. Furthermore, they found that the spending of patients with persistent high-cost status was mostly due to outpatient care and drugs. Although we examined a subgroup of patients with high-cost status, we also found that more patients with mental illness and persistent high-cost status lived in lower-income areas than patients with mental illness and moderate and sporadic high-cost status. However, these patients' spending profile was substantially different - most costs were due to psychiatric hospital admissions, further confirming the need to consider them separately from other high-cost patients. In line with Figueroa and colleagues, we also found that a small proportion of spending was due to preventable acute-care hospital admissions among patients with mental illness and high-cost status. This is not surprising as most costs were due to psychiatric hospital admissions and not acute-care admissions. Therefore, it may make more sense to try to ascertain preventable psychiatric hospital admissions, where possible. Although some psychiatric hospital admissions are likely part of the natural course of the disease, and thus inevitable, some admissions to hospital, namely readmissions, could potentially be prevented through timely access to physician care ${ }^{33}$ and adherence to medication. ${ }^{34}$ This should be explored in future research. Also, as a nontrivial number of patients persisted in the high-cost state for 8 years, models predicting long-term persistency may also prove useful for decision-makers. This may require a better understanding of how to prevent multimorbidity from developing among individuals with severe mental illness; for example, through screening of chronic conditions where appropriate. ${ }^{35}$

We examined all adult patients with mental illness and highcost status in Ontario; previous work has typically examined representative samples or patients aged 65 years and older only. We followed patients for 8 years; most related work has followed patients for 3 years. Finally, we captured most health care services paid by the Ontario Ministry of Health. Although there is a large body of work on all patients with high-cost status, ${ }^{9,36,37}$ little attention has been devoted to those with mental illness or examined their trajectories of care. ${ }^{4}$ At a health-systems level, this research will help inform interventions that preserve quality of care while reducing costs, including preventing persistence in the high-cost state. Previous literature suggests that patients with persistent high-cost status may be an ideal focus for cost-saving interventions, as some costs may be reduced through proper disease management. ${ }^{28}$ For example, high support housing ${ }^{38}$ may help address long hospital stays, which are a driver of high costs. However, our results suggest there may be little scope to address these patients' high costs without further understanding the reasons for high hospital admission costs and for related outcomes such as long lengths of stay in hospital. These findings may be useful to inform initiatives that focus on improving the management of care among complex, high-need patients with medical and psychiatric multimorbidity, such as the Health Links Initiative in Ontario, ${ }^{39}$ Accountable Care Organizations ${ }^{5}$ in the US and the Better Care Fund ${ }^{40}$ in the United Kingdom. ${ }^{40}$

\section{Limitations}

We did not examine children and adolescents, as some health services for this population are funded by ministries other than the Ministry of Health. We could not capture patients who did not access the health care system via settings for which we did not have data. For example, we were not able to include the costs of community-based addiction-related care. We were able to capture only costs of outpatient drugs covered by the public provincial drug plan (although this was in line with the perspective of the analysis). The lack of these costs may have affected how patient cohorts were determined. Furthermore, we were able to examine only chronic conditions for which there were validated algorithms. This was particularly problematic for psychiatric conditions as there is a validated algorithm only for psychosis (the mood disorders algorithm is not validated and its definition was limited to the quality of the Ontario physician billings data; moreover, it likely underestimates the number of patients with mood disorders). Additionally, because of data limitations, we were not able to characterize patients in terms of their ethnicity or race, as was done in previous research. ${ }^{5}$

\section{Conclusion}

Many patients with mental illness and high-cost status persisted in the high-cost state, particularly those in low-income or urban areas and with comorbidities. The higher costs incurred by this group were driven by psychiatric hospital admissions. Policymakers should consider interventions that address quality of care through the management of psychosis and multimorbidity and high health care costs, as well as appropriate prevention policies aimed at patients with mental illness before they enter the persistent high-cost state. More research is required to understand what more can be done to address persistency in the highcost state and whether there may be potential to reduce psychiatric hospital admission or the length of hospital stays.

\section{References}

1. Chechulin $\mathrm{Y}$, Nazerian A, Rais S, et al. Predicting patients with high risk of becoming high-cost healthcare users in Ontario (Canada). Healthc Policy 2014;9:68-79.

2. Rosella LC, Fitzpatrick T, Wodchis WP, et al. High-cost health care users in Ontario, Canada: demographic, socio-economic, and health status characteristics. BMC Health Serv Res 2014;14:532. 
3. Wammes JJG, van der Wees PJ, Tanke MAC, et al. Systematic review of high-cost patients' characteristics and healthcare utilisation. BMJ Open 2018;8:e023113.

4. de Oliveira C, Cheng J, Vigod S, et al. Patients with high mental health costs incur over 30 percent more costs than other high cost patients. Health Aff (Millwood) 2016;35:36-43.

5. Powers BW, Chaguturu SK. ACOs and high-cost patients. N Engl J Med 2016;374:203-5.

6. de Oliveira C, Cheng J, Rehm J, et al. The role of mental health and addiction among high-cost patients: a population-based study. J Med Econ 2018;21:348-55.

7. Wodchis WP, Austin PC, Henry DA. A 3-year study of high-cost users of health care. CMAJ 2016;188:182-8.

8. Figueroa JF, Zhou X, Jha AK. Characteristics and spending patterns of persistently high-cost Medicare patients. Health Aff(Millwood) 2019;38:107-14.

9. Riley GF. Long-term trends in the concentration of Medicare spending. Health Aff (Millwood) 2007;26:808-16.

10. Monheit AC. Persistence in health expenditures in the short run: prevalence and consequences. Med Care 2003;41(Suppl):III53-64.

11. Chang H-Y, Boyd CM, Leff B, et al. Identifying consistent high-cost users in a health plan: comparison of alternative prediction models. Med Care 2016;54:852-9.

12. Wodchis W, Bushmeneva K, Nikitovic M, et al. Guidelines on person-level costing using administrative databases in Ontario. Working Paper Series Vol. 1. Toronto: Health System Performance Research Network; 2013.

13. Wodchis WP, Austin PC, Henry DA. A 3-year study of high-cost users of health care. CMAJ 2016;188:182-8.

14. Antoniou T, Zagorski B, Loutfy MR, et al. Validation of case-finding algorithms derived from administrative data for identifying adults living with human immunodeficiency virus infection. PLoS One 2011;6:e21748.

15. Benchimol El, Guttmann A, Mack DR, et al. Validation of international algorithms to identify adults with inflammatory bowel disease in health administrative data from Ontario, Canada. J Clin Epidemiol 2014;67:887-96.

16. Gershon AS, Wang C, Guan J, et al. Identifying patients with physician diagnosed asthma in health administrative databases. Can Respir J 2009;16:183-8.

17. Gershon AS, Wang C, Guan J, et al. Identifying individuals with physician diagnosed COPD in health administrative databases. COPD 2009;6:388-94.

18. Hux JE, Ivis F, Flintoft V, et al. Diabetes in Ontario: determination of prevalence and incidence using a validated administrative data algorithm. Diabetes Care 2002;25:512-6

19. Jaakkimainen RL, Bronskill SE, Tierney MC, et al. Identification of physiciandiagnosed Alzheimer's disease and related dementias in population-based administrative data: a validation study using family physicians' electronic medical records. J Alzheimers Dis 2016;54:337-49.

20. Kurdyak P, Lin E, Green D, et al. Validation of a population-based algorithm to detect chronic psychotic illness. Can J Psychiatry 2015;60:362-8.

21. Moist LM, Fenton S, Kim JS, et al. Canadian Organ Replacement Register (CORR): reflecting the past and embracing the future. Can J Kidney Health Dis 2014;1:26.

22. Prodhan S, King MJ, De P, et al. Health services data: the Ontario Cancer Registry (a unique, linked, and automated population-based registry). In: Levy A, Goring S, Editors. Data and Measures in Health Services Research. Health Services Research; 2016.
23. Schultz SE, Rothwell DM, Chen Z, et al. Identifying cases of congestive heart failure from administrative data: a validation study using primary care patient records. Chronic Dis Inj Can 2013;33:160-6.

24. Tu K, Chen Z, Lipscombe LL; Canadian Hypertension Education Program Outcomes Research Taskforce. Prevalence and incidence of hypertension from 1995 to 2005: a population-based study. CMAJ 2008;178:1429-35.

25. Widdifield J, Bernatsky S, Paterson JM, et al. Accuracy of Canadian Health administrative databases in identifying patients with rheumatoid arthritis: a validation study using the medical records of rheumatologists. Arthritis Care Res (Hoboken) 2013;65:1582-91.

26. Greene WH. Econometric analysis. 7th ed. Upper Saddle River (NJ): Prentice Hall; 2012.

27. Engel J. Polytomous logistic regression. Stat Neerl 1988;42:233-52.

28. Billings J, Mijanovich T. Improving the management of care for high-cost Medicaid patients. Health Aff (Millwood) 2007;26:1643-54.

29. Johnston KJ, Allen L, Melanson TA, Pitts SR. A "Patch" to the NYU Emergency Department Visit Algorithm. Health Serv Res. 2017;52(4):1264-1276.

30. Prevention quality indicators overview. Rockville (MD): Agency for Healthcare Research and Quality; 2020. Available: www.qualityindicators.ahrq.gov/Modules /pqi_resources.aspx (accessed 2018 Dec. 17).

31. de Oliveira C, Cheng J, Rehm J, et al. The economic burden of chronic psychotic disorders in Ontario. J Ment Health Policy Econ 2016;19:181-92.

32. Kurdyak P, Vigod S, Duchen R, et al. Diabetes quality of care and outcomes: Comparison of individuals with and without schizophrenia. Gen Hosp Psychiatry 2017;46:7-13.

33. Kurdyak P, Vigod SN, Newman A, et al. Impact of physician follow-up care on psychiatric readmission rates in a population-based sample of patients with schizophrenia. Psychiatr Serv 2018;69:61-8.

34. Higashi K, Medic G, Littlewood KJ, et al. Medication adherence in schizophrenia: factors influencing adherence and consequences of nonadherence, a systematic literature review. Ther Adv Psychopharmacol 2013;3:200-18.

35. Severe mental illness (SMI) and physical health inequalities: briefing. London (UK): Public Health England; 2018. Available: www.gov.uk/government/publications/ severe-mental-illness-smi-physical-health-inequalities/severe-mental-illness-and -physical-health-inequalities-briefing (accessed 2020 May 8).

36. Cohen SB. The concentration and persistence in the level of health expenditures over time: estimates for the U.S. population, 2009-2010. Statistical Brief No 392. Rockville (MD): Agency for Healthcare Research and Quality; 2012. Available: www.meps.ahrq.gov/mepsweb/data_files/publications/st392/ stat392.shtml (accessed 2020 May 8).

37. Rais S, Nazerian A, Ardal S, et al. High-cost users of Ontario's healthcare services. Healthc Policy 2013;9:44-51.

38. Rudoler D, de Oliveira C, Jacob B, et al. Cost analysis of a high support housing initiative for persons with severe mental illness and long-term psychiatric hospitalization. Can J Psychiatry 2018;63:492-500.

39. Coordinated care management for patients with mental health and/or addictions conditions. Toronto: Health Quality Ontario. Available: www.hqontario. ca/Quality-Improvement/Quality-Improvement-in-Action/Health-Links/Health -Links-Resources/Coordinated-Care-Management-for-Patients-with-Mental-Health -and-or-Addictions-Conditions (accessed 2020 May 8).

40. Better Care Fund. London: NHS; 2020. Available: www.england.nhs.uk/ ourwork/part-rel/transformation-fund/bcf-plan/ (accessed 2020 Nov. 25).

\section{Competing interests: None declared.}

This article has been peer reviewed.

Affiliations: Centre for Health Economics and Hull York Medical School (de Oliveira), University of York, York, UK; Institute for Mental Health Policy Research (de Oliveira, Mason, Kurdyak), Centre for Addiction and Mental Health; ICES (de Oliveira, Mason, Kurdyak); Institute of Health Policy, Management and Evaluation (de Oliveira, Kurdyak), and Department of Psychiatry (Kurdyak), University of Toronto, Toronto, Ont.

Contributors: Claire de Oliveira conceived and designed the work; contributed to the acquisition, analysis and interpretation of data; and drafted the manuscript. Joyce Mason and Paul Kurdyak contributed to the acquisition, analysis and interpretation of data. All of the authors revised the manuscript critically for important intellectual content, gave final approval of the version to be published and agreed to be accountable for all aspects of the work.
Data sharing: The data from this study are held securely in coded form at ICES. While data sharing agreements prohibit ICES from making the data publicly available, access may be granted to those who meet prespecified criteria for confidential access, available at www.ices.on.ca/DAS.

Disclaimer: This research was funded by the Canadian Institutes of Health Research (CIHR) and supported by ICES, which is funded by an annual grant from the Ontario Ministry of Health and Long-term Care (MOHLTC). The opinions, results and conclusions reported in this paper are those of the authors and are independent from funding sources. No endorsement by CIHR, ICES or the Ontario MOHLTC is intended or should be inferred. Parts of this material are based on data and information compiled and provided by the Canadian Institute for Health Information (CIHI). However, the analyses, conclusions, opinions and statements expressed herein are those of the authors, and not necessarily those of $\mathrm{CIHI}$.

Accepted: Aug. 6, 2020

Correspondence to: Claire de Oliveira, claire.deoliveira@york.ac.uk 